FEMALES.

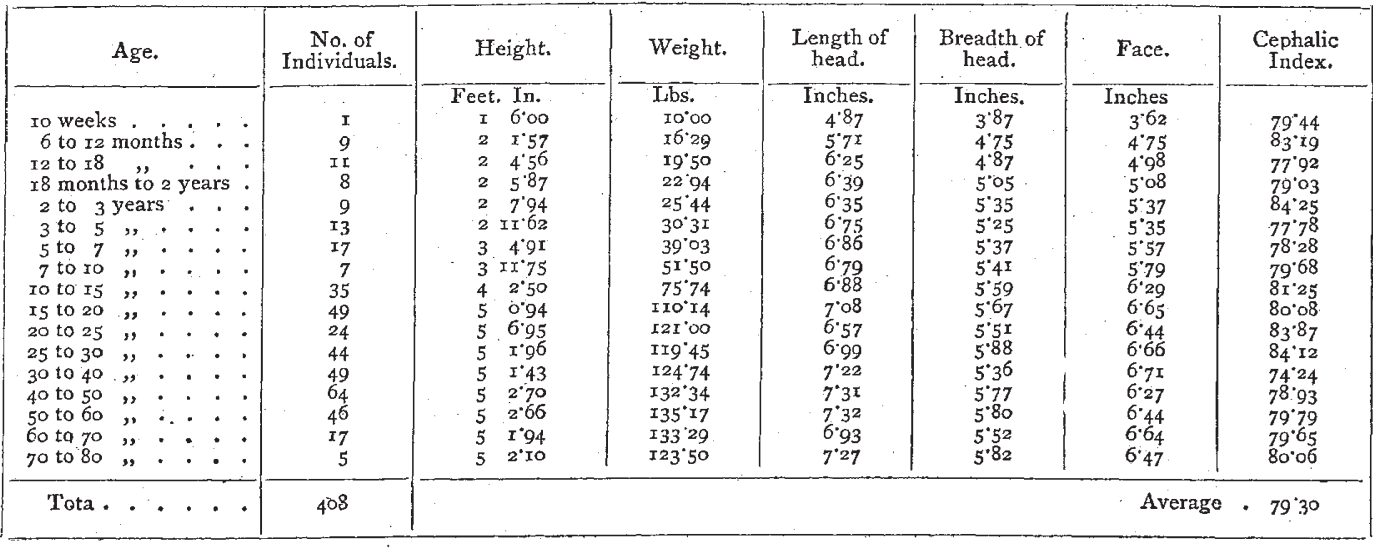

\section{ONE SOURCE OF SKIN DISEASES}

0

BSCURE affections of the skin. of the face of men especially are well known to specialists to be widely spread. They are commonly classed as ekzema, and while causing great discomfort especially at night, show nothing, or almost nothing, to the eye, if the patient be otherwise in pretty good health. Skin specialists frequently ask patients whether they have been using any new sort of soap, but no one seems hitherto to have traced any distinct communication between soap and this troublesome disease.

As I have been able pretty distinctly to do so in reference to myself, probably a brief notice of the facts may not be out of place in NATURE, where it is likely to be of more popular benefit than if committed to the pages of a medical journal, in which the inferences of "mere laymen" are not greatly reputed. It is a fact but very little known to the multitude of both sexes who use the "Prime Old Brown Windsor Soap" of the perfumers' shops, that by far the largest proportion of it is manufactured from "bone-grease." Few more beautiful examples of chemical transformation are to be found in the whole range of chemical manufacture than this one. At one end of a long range of buildings we find a huge shed heaped up with bones, usually such as are of little value to the bone-turner or brush-maker, in all stages of putrefaction as to the adherent or inherent portions of softer animal matter attached to them, the odour of which is insupportable.

These are crushed and ground to a coarse powder, exposed to the action of boiling water under pressure, sometimes of steam, until the grease and marrow are extracted.

We need not here pursue the subsequent treatment of the rest of the material from which bone glue and "patent isinglass" are prepared, the latter of which we often eat in the soups and jellies of the pastrycooks, and finally to the "bone dust," or phosphate of lime, nearly free from animal matter," which is produced for the use of the assayer and the china manufacturer. \&c., as well as for other purposes in the arts.

But let us follow up the bone-grease, which is of a dark tarry brown colour, and of an abominable odour.

By various processes it is more or less defæcated, bleached, and deodorised, and is separated into two or three different qualities, the most inferior of which goes to the formation of railway or other machinery greases, and the latter is saponified, and becomes, when well manufactured, a hard brown soap, still, however, retaining an unpleasant smell. It is now, after being remelted, strongly perfumed, so that, like the clothes and persons of the magnates of the Middle Ages, its own evil odour is hidden by the artificial perfume.

This is the "Fine Old Brown Windsur Soap" of most of our shops. The natural brown colour of the grease gives it the right tint in the cheapest way, without the colouring by caramel, which was the original method of manufacture.

Like all other things, there are cheap and dear Windsor soaps; and for the production of the former little is done beyond saponifying and casting into blocks or bars. Were we to rely upon the many experiments that have been made as to the degree of elevation of temperature at which putrescent or other contagious matter is deprived of its morbific power, we might conclude that boiling and saponifying had made this hitherto putrescent grease innocuous.

It seems, however, more than doubtful that such is the fact in this case, for the soap thus made seems to be capable of communicating skin diseases when rubbed on the face for use in shaving.

But another promoter of irritation is not unfrequently also found. Whether it be that it is more profitable to the soapmaker to have a liberal proportion of the finer particles of the ground bone made up with the soap, or that these are difficult to separate completely, the fact is that bars of this "Brown Windsor Soap" are to be bought containing a rich mixture of those small sharp angular fragments of bone which before boiling was putrid. When a piece of such soap is rubbed hard to a man's face, the skin is more or less cut and scored by these bony particles held in the soap like emery in a head "lap," and thus the skin is placed in the most favourable state to absorb whatever there may be of irritant, or contagious, or putrid in the soap itself. The existence of the bone fragments is easily verified by solution of the soap in water or alcohol, and examination of the undissolved particles with a lens; and I can readily, if need be, send you a piece of such soap for examination.

Now, without occupying too much of your space; I may just state that I have while using such shaving soap thrice suffered from ekzema of the face. On the first occasion I derived no benefit from treatment by the two most celebrated dermal surgeons in London, and at last the disease went away of itself after giving up shaving for a time. I had by me a quantity of this brown soap, and through inadvertence took to using it again, for a time without effect ; but when dry and hot weather came, with it came a recurrence of the skin disease, which also again, after some months of discomfort, went away. Curious to make sure 
whether or not the soap was the real cause, I a third time employed the soap deliberately to see if the ekzema was due to it. I was in excellent health, and in about three weeks. I found the disease reestablished, so that I think the soap must be viewed as found guilty. Good white unscented curd soap is now my resource, and with no ill-effects.

Ekzema is always a distressing complaint even when affecting those in the most robust health. With those of bad constitution or lowered health, however, it seems to degenerate into bad or intractable skin diseases, so that probably this notice may not be deemed useless or uncalled for.

R. M.

\section{THE SCHOOL OF MILITARY ENGINEERING}

THERE are few educational establishments, in this country at any rate, that fulfil their object so aptly and so well, as the School of Military Engineering at Chatham. When we remember the many sciences and technical accomplishments with which the officers of the Royal Engineers are conversant, and the practical use that many of them are required to make of their acquirements, it is very obvious indeed that, to be successful, the system of education must be a most complete and substantial one. It is, in truth, necessary that a man entering either of the scientific corps of the army-the Royal Artillery or Royal Engineers-should not only be intuitively quick and clever, so as to grapple with the multifarious subjects of study, but it is moreover quite as indis. pensable that he should be at the outset sufficiently strong and healthy to withstand the wear and tear of so much hard work. To become a Mr. Toots would, we fear, be the fate of many young gentlemen, were they passed through the Woolwich Academy, and into these departments of the Army, without first undergoing a rigid medical examination; for the severe and lengthy curriculum is such as would certainly jeopardise the health of any but the strongest constitutions. Commissions in the Royal Artillery and Royal Engineers, be it remembered, have for many years past been obtainable only by open competition, the successful candidates being admitted into the Royal Military Academy, whence they are passed into the Army when found properly qualified. But to compete successfully for admission to the Academy in the first instance, involves already a knowledge of mathematics, of experimental and applied sciences, of languages, and other subjects too numerous to detail, such indeed as is scarcely possessed by other well-educated professional men; and this, bear in mind, is but the starting-point of the scientific soldier's education. At the Academy, where the course of special instruction sometimes continues for three years, he has to pass from a lower to an upper section, and when successfully through the examinations that beset him at every turn, he receives his commission in a provisional sort of way only. The successful Academicians highest on the list are sent to Chatham, to commence instruction in their duties as Royal Engineers, while the remainder complete their education at Woolwich and Shoeburyness, as lieutenants in the Royal Artillery. And if, after all this, there are yet dissatisfied spirits, who still exhibit a craving for more, then there is the staff college, the advanced class, instruction certificates, and other ends to be attained, enough in all conscience to satisfy the most ambitious.

It is to the School of Military Engineering that the young lieutenants of Engineers are sent for instruction in their various duties, and it is only after passing through a two years' course at this establishment that their commissions are actually secured to them. The professors, or instructors, as they are termed, are all officers of some years' standing in the corps, appointed by reason of their intimate acquaintance with the special subjects that they teach. These subjects are not only very various, but are, moreover, always increasing, as our system of warfare continually improves. Thus, besides the subjects of surveying, construction, estimating, fortifications, telegraphy, and other more ordinary, though not less practical, matters, there have been added of late years, chemistry, photography, army signalling, torpedo service, \&c., all of which the Royal Engineer must know something about:

It is evident that mere theoretical instruction in matters like these would be of little use to men who occupy such practical appointments as are filled by most Engineer officers, and it is in this respect that the School of Military Engineering may claim superiority over kindred establishments. The studies, workshops, laboratories, and demonstrating. schools are of the most complete description, while the outworks and broken ground upon the Chatham lines and around the Brompton Barracks afford ample scope for the practical prosecution of those-studies which require a wide field of operations. It is this practical manner of going about one's duties that is calculated above all things to impart a thorough knowledge, and to inspire officers with true confidence in their abilities. Fortifications are designed, parallels drawn, mines prepared, bridges constructed, and other siege duties executed by the students themselves, to render them conversant with their duties practically as well as theoretically, while the appointment of temporary telegraph stations, the experimental application of explosive and torpedo charges, the actual exercise of signalling, both by day and night, impart experience which could not, of course, be gained by teaching or lectures in the schools.

But it is not only the officers who benefit by the Engineering School at Chatham. The non-commissioned officers, also, are required to attend instruction in field works, and can, indeed, if they desire it, pass through the entire system of study, a course imperative on all those desirous of promotion to "foremen of works," or to other similar positions. The sappers, too, are well acquainted with at least one trade, or calling, and as every company of Engineers is made up from a due proportion of all rades, it is obvious such a complete and intelligent body of men is ofttimes invaluable. Thus it is that, in the Colonies, in Australia, New Zealand, South Africa, ind other stations where detachments of Royal Engineers have been sent, their services have been found so truly valuable, every available talent being at once at hand for the carrying out of the engineering and other kindred duties necessary to be fulfilled in the occupation of a rough untravelled country. As an instance of this, we need point merely to the recent Abyssinian Campaign, which may justly be called a triumph of engineering-a gigantic piece of road-making in fact-rather than a victory over half-naked Africans; for here we have in something like six months, a rough tract of country surveyed and mapped out, four hundred miles of road made, aline of railway laid down, telegraph communication established, wells sunk, and all this over and above the transport of a large body of men and war material.

The subject of torpedoes and submarine mines was so recently discussed in these columns, that we need not again refer at any length to this latest military science just now under special investigation at Chatham. But before concluding these few remarks, we may make mention of some experiments upon an extensive scale that were not long since made with these terribly destructive machines. The charges were fired from the shore by means of electricity, the signal for their discharge being given from the distance almost of a mile; and to show the control and certainty exercisable in the system employed, there was, in one instance, a steamer made to pass harmlessly over one of the charges; which immediately afterwards, at a yiven signal, blew into framents a lainch following in tow 